\title{
ADDRESS STRATEGIES IN A BRITISH ACADEMIC SETTING
}

\author{
Maicol Formentelli
}

\begin{abstract}
The English system of address constitutes an exception among the European languages, in that it does not have a grammatical distinction between a formal pronoun of address and an informal one. Rather, English speakers exploit lexical strategies (i.e. nominal vocatives). This study aims to shed light on the address strategies used by students and members of the teaching staff in academic interactions, with reference to the University of Reading (UK). Data from semi-structured interviews and video-recordings outline an unmarked pattern of asymmetry between the parties, in which students mainly employ formal vocatives towards lecturers (title+surname, honorifics), while lecturers frequently use first names and other informal expressions. Reciprocal informal vocatives, by contrast, emerges as a marked practice, which is resisted or delayed in time. This asymmetrical distribution of forms questions classical models and previous research on address and calls for the necessity of new components for the understanding of the phenomenon.
\end{abstract}

Keywords: Terms of address; Academic setting; Classroom interactions; British English.

\section{Introduction}

The use of language in interaction entails more than just exchanging information about thoughts and factual things from one person to another: It is an important circumstance in which the relationships among people are defined and negotiated. While engaging in conversations people consciously or unconsciously show their identities, their belonging to a specific culture or social group and their desire to come close or distance themselves from others. A significant area of language in which all these functions are highlighted is terms of address. These are almost never neutral in the interpersonal meaning they convey, as the choice of a particular form inevitably entails the expression of feelings and attitudes, and it is the result of an evaluation of the interlocutor and of the nature of the relationship holding between the participants. Terms of address have also been defined "a sociolinguistic subject par excellence" (Philipsen and Huspek 1985: 94), since the usage of these forms reflects the social and linguistic background of interactants to a greater extent than other aspects of language.

This article focuses on a specific domain of address, namely the address strategies employed by British English speakers in interactions within the academic setting, which has been indirectly and only marginally discussed in the previous literature (cf. Dickey 1997; Bargiela et al. 2002) and lacks systematic up-to-date investigation. A picture of address behaviours in academic settings is interesting not only for the understanding of human interactions from a linguistic and sociological point of view, but also for the implications it may have for fields such as English language teaching 
and intercultural communication (Axelson 2007), given the increasing number of students from countries all over the world who choose British universities for tertiary education. The phenomenon of address is in fact often neglected in grammars and the lack of linguistic competence on the part of speakers might lead to misuse of forms and misunderstandings in intercultural discourse (cf. Pieper 1990). This paper thus tries to shed light on some important aspects of address in academic encounters, such as the occurrence of verbal and non-verbal patterns of address, the alternation between pronominal and nominal forms, the level of formality expressed by students and lecturers, and the influence of power and hierarchical relations on the distribution of address strategies. This investigation, which takes the form of a case study involving the University of Reading (Berkshire, UK), is an attempt to establish a starting point for further research on the topic, which would lead to an up-to-date description of address practice in the British academic environment in general.

\section{Aspects of address theory}

The classic and most influential contribution to the research on the phenomenon of address was published by Brown and Gilman (1972 [1960]; see also Gilman and Brown 1958), who investigated the usage of pronominal address forms in some European languages and provided a universal model based on the dichotomic distinction between an informal, familiar pronoun (T) and a formal, polite pronoun (V). According to the authors, the choice of address pronouns is regulated by the two complementary dimensions (or semantics) of power and solidarity, which can be applied to all interactional dyads.

The power semantic is basically a vertical, asymmetrical relationship between speaker and addressee due to a difference of power, which is reflected in the nonreciprocal use of pronouns. The solidarity semantic, by contrast, is characterized by the reciprocal use of terms in relationships among equals, which vary according to the degree of closeness and intimacy. Brown and Gilman (1972 [1960]) maintain that the solidarity behaviour has confined the semantics of power and dominance to a minority of social situations, and that the mutual use of familiar forms is taking over to the usage of reciprocal distancing pronouns.

The power-and-solidarity model has been positively welcomed by the research community for its attempts to systematically describe such a complex phenomenon (among others Brown and Ford 1964 [1961]; Ervin-Tripp 1986; Braun 1988; Mühlhäusler and Harré 1990; Wales 1996). The theory, however, has also been object of discussions and debates, which has resulted in modifications also in recent studies on this topic.

One limitation of Brown and Gilman's theory concerns the suggested universality of the dichotomic distinction T/V (cf. Helmbrecht 2003, 2005). Many languages, in fact, do not display a pronominal distinction as a strategy to convey politeness and respect (e.g. English), others are characterized by multiple distinctions in their pronominal paradigm (e.g. Romanian, Hungarian, Kannada, Tamil), some just avoid the use of personal pronouns in addressing people directly and employ complex nominal expressions (e.g. Japanese, Thai, Korean). Even languages with T/V dichotomy show a wider variation in their address systems, combining pronouns, nominal forms and honorifics in a scalar rather than binary way (cf. Clyne et al. 2006). 
Brown and Gilman's model has been particularly useful in the investigation of patterns of address in American English, both in past research (Brown and Ford 1964 [1961]) and in a recent study (Murray 2002), which show results consistent with the theory of power and solidarity. In Brown and Gilman's terms, the tendency in interactions among American English speakers appears to be the rapid abandonment of the asymmetrical power semantic and of the reciprocal use of distancing forms in favour of the symmetrical solidarity dimension of intimacy and familiarity.

By contrast, the linear evolution towards informality and solidarity postulated by Brown and Gilman does not seem to be fully satisfactory for other languages. A largescale comparative project aimed to describe variation and change in the address systems of French, German and Swedish (Clyne et al. 2004, 2006, 2009; Warren et al. 2007) has recently called into question the linear progression from formal to informal address. On the basis of a broad corpus of data, Clyne and his colleagues outline a certain dynamism and variation in the choice of address forms in these languages, which lead to a greater opportunity of negotiation of terms in interaction. They argue that "changes in address systems are not necessarily linear but may be cyclical" (Clyne et al. 2006: 314, emphasis added), as a result of the modification of the address rules described in the past and the re-emergence of $\mathrm{V}$ forms which were abandoned under the influence of specific linguistic policies (e.g. the formal pronoun ni in Swedish). The cyclical variation of address behaviour is in strong contrast with the linear evolution assumed by Brown and Gilman in the 1960s and calls for a redefinition of the parameters of the model to account for the complex mechanisms underlying the phenomenon of address.

At present, none of the models and theories on address discussed above has been tested on British English and British academic settings in particular. Indeed, address practice in the domain of British academic encounters has been only partially investigated in previous research and deserves greater attention.

Dickey (1997), for instance, sheds some light on the use of forms of address and terms of reference in academic interactions, but analyzes data from both American and British environments without making any distinction between the two cultures and language varieties.

Bargiela et al. (2002), in their investigation of naming strategies in intercultural business encounters, focus on the frequent use of first names and informality on the part of English native speakers in addressing non-acquainted people. The authors claim that such politeness strategies of involvement are "an indicator of ease of communication with strangers" (2002: 1) for many British and American speakers. These strategies, however, can be offensive if employed in interactions with people from other linguistic and cultural backgrounds. Later in the paper, they argue that the growing informality of address in institutional encounters is relatively recent in the United Kingdom and is part of the process of Americanization of British culture. They suggest that not all British people are comfortable with the use of reciprocal first name in initial encounters and that this practice is still considered inappropriate by many speakers. As for the domain of academic interactions, Bargiela et al. suggest that the use of reciprocal first name with lecturers is common in British universities, but some students are not comfortable with it and find it too familiar. Hence, a certain amount of dispreference and resistance on the part of students in the use of informality in the classroom can be suggested for British universities. This would contrast with one of the main points of Brown and Gilman's model, namely the rapid switch to mutual informal address. Moreover, it 
would necessarily require a revision of the distribution of power in the dyad, with a reassessment of the role of less powerful participants in regulating the evolution of the relationship towards informality.

Empirical investigation in the domain of British academic interactions is thus needed to evaluate the efficacy of Brown and Gilman's model and the findings of previous work on address, which seems to be biased towards American English and American culture.

\section{English system of address}

As is well known, English constitutes an unusual case in address if compared to the other languages in Europe (Hickey and Stewart 2004; Helmbrecht 2003. 2005, 2006). English, in fact, is characterized by a reduced pronominal paradigm which does not distinguish between a formal and an informal address pronoun. Consequently, in this language intimacy and deference cannot be conveyed through a binary address system based on $\mathrm{T} / \mathrm{V}$ pronouns ${ }^{1}$.

The usage of the unique second-person pronoun you in standard English is generally associated with an idea of neutrality and can be considered a strategy of avoidance available to speakers as they are not obliged to express any overt stance of respect or familiarity towards their interlocutor ${ }^{2}$. In other words, English does not display a pronominal codification of social deixis in interactions.

The most effective strategies of address in English are rather lexical, which means a proliferation of noun phrases and nominal expressions employed by speakers to convey interpersonal meanings (cf. Dunkling 1990; Leech 1999; Biber et al. 1999: 1108-1109 for a classification). Nominal address terms are characterized by a high degree of syntactic freedom within the utterance and are commonly referred to as vocatives for their distinctive intonation profile (Zwicky 1974). Moreover, they constitute a very productive lexical category, which is open to addition, substitution and combination of forms, creating complex interrelations among several distinct subgroups.

Roughly speaking, nominal forms of address express different degrees of formality/informality and can be ordered on a scale of intimacy/distance. However, it is the context of use and the relationship between the parties that determines the precise nuances of meaning. For instance, titlestlast names and honorifics usually express formality and distance towards addressees of high social status, but they can also communicate solidarity if they are used with a jocular tone among friends. A similar consideration is valid for invectives and expletives, which generally convey hostility and aggressiveness, but can also be employed reciprocally as covert familiarizers to express camaraderie among male friends (McConnel-Ginet 2003: 82) or affection among close female friends (Sutton 1995).

1 The distinction between singular and plural second-person pronominal forms is productive in regional and vernacular varieties of English in Europe and overseas (cf. Hickey 2002), although none of them developed a $\mathrm{T} / \mathrm{V}$ system of address similar to the one common in the languages of continental Europe, despite the prolonged contacts with other languages such as French in Canada or Spanish in southern United States.

2 Nonetheless, the use of you as vocative in imperatives and the insisted repetition of such pronoun within the same utterance can take on the negative connotation of abruptness, hostility and imposition on the addressee. 
To sum up, in spite of the apparent simplicity of address strategies entailed in the reduction of forms in the pronominal paradigm, social deixis in English is expressed through a wide and elaborated repertoire of nominal expressions, which are regulated by sociolinguistic and contextual parameters like gender, social class, status, nature of the relationship between the parties and type of encounter.

\section{The study}

The present study aims to give an up-to-date picture of the practice of address among students and members of the teaching staff at the University of Reading (Berkshire, UK) discussing it in relation to well-established models and recent research on address systems. The attempt is to add insights to the research on the phenomenon of address in English speaking countries, which includes a large number of valuable contributions, both theoretically and empirically, but which has concentrated almost entirely on American English and very little on other varieties such as British English.

This survey was conducted following an ethnographic approach (Gumperz and Hymes 1972), with the integration of the researcher in the daily social activities on campus. In order to overcome the problems entailed in the choice of a speech community (cf. Duranti 1997 and Saville-Troike 2003), the domain of interest for this study was broadly defined as all those people living and/or working on campus at the University of Reading who use British English as the main language of communication in the academic environment ${ }^{3}$. Particular attention was given to three types of teaching activities (lectures, seminars and tutorials), which constitute the main everyday social interactions among students and members of the teaching staff.

The corpus of data, collected over a nine-month period of field research in this institution, integrates a range of methodologies, including participant observation, semi-structured interviews and video-recordings of teaching activities ${ }^{4}$. This allows a combination of qualitative and quantitative analyses of the main social factors and contextual variables that regulate the distribution of address forms in academic interactions, as well as an evaluation of the participants' perception of the educational implications entailed in the strategies employed.

Participant observation was particularly useful in the early stages to identify the categories of forms employed in interactions and to formulate hypotheses about the parameters and mechanisms regulating the phenomenon of address. Data were then elicited through semi-structured interviews with 26 respondents (18 students and 8

3 The speech community includes British English native speakers, bilingual British English native speakers (people born and grown up in Britian with at least one parent speaking another language) and students who speak British English as a foreign language. This last group has been excluded from the sample of informants used in the collection of data.

${ }^{4}$ The recordings and transcriptions used in this study come from the British Academic Spoken English (BASE) corpus. The corpus was developed at the Universities of Warwick and Reading under the directorship of Hilary Nesi and Paul Thompson. Corpus development was assisted by funding from BALEAP, EURALEX, the British Academy and the Arts and Humanities Research Council.

Excerpts from interviews and video-recordings have been transcribed as plain text, without indicating punctuation, pauses, hesitation markers, laughter and intonation patterns. 
lecturers) of different gender, age range, social class ${ }^{5}$, region of origin and subject. This allowed to gather a great amount of information about the distribution of address strategies in academic interactions and the attitudes of speakers towards the vocatives employed. Video-recordings of teaching activities (one lecture, three seminars and one practical session) were also included in the corpus to provide instances of naturally occurring speech and to cross-check the picture provided by the responses of informants ${ }^{6}$.

In what follows, an analysis of the distribution and patterns of use of nominal and pronominal address terms in academic interactions at the University of Reading is attempted, with particular attention to the social and contextual factors that influence the choice of address strategies on the part of speakers.

\section{Address strategies in the classroom: Lecturers, instructors and students}

From the data collected through interviews, four main address strategies may be identified in interactions among students and members of the teaching staff: title + last name (TLN), first name (FN), honorific (HON) and avoidance (no explicit form of address).

\subsection{Addressing lecturers}

From the responses provided by students in the interviews, a general formality in addressing lecturers emerges. In fact, a large group of informants (39\%) employs TLN in interactions in the classroom, making explicit reference to the addressee's occupational status within the academic hierarchy (i.e. Professor or Doctor).

(1) 'I never use their first name or I try not to I choose their last name and what the status is like if he's a doctor I try to say Doctor [surname] in case you offend them by not giving their status.'

(Male student, 19 years old).

(2) 'I don't like calling lecturers by their first name [...] no I don't like it if they are doctors then I go as Doctor Smith.'

(Female student, 20 years old).

Moreover, the trend of formality seems to be confirmed by the use of HONs (28\%), which are quite a common strategy exploited by both male and female students in alternation with TLN to express the highest degree of respect. The HON frequently

${ }^{5}$ The social class has been determined following the 'class schema' developed by Goldthorpe (2000), which proposes correspondence between social classes, forms of occupation and employment relations. Students' parents' occupations and levels of education have been considered in this study.

6 The teaching activities used to cross-check informants' responses were recorded at the University of Warwick (Warwick component of the BASE corpus), which is comparable to the University of Reading in many aspects. The main focus of this study, however, remains on the address strategies employed by lecturers and students at the University of Reading, which have been investigated in more details through participant observation and semi-structured interviews. 
employed in addressing lecturers is the masculine form Sir, whereas the parallel feminine forms madam and ma'am have not been mentioned by informants.

On the other hand, the use of $\mathrm{FN}$ as exclusive strategy in addressing lecturers appears to be limited to a minor part of students $(22 \%)$, who justify their choice by arguing against the distancing power of formal titles and praising the beneficiary effects of familiar forms in establishing a better relationship with the teaching staff. This is described in the following comment by one of the informants:

(3) 'If they [i.e. professors] don't mind you call them by their first name you feel like you have a better relationship with them and even though they are so higher in status you feel that you have sort of a better relationship so it kind of helps you it makes it easier to work with them instead of feeling as if you've been watched and persecuted all the time.'

(Male student, 21 years old).

In spite of the apparent clear-cut distribution of address strategies reported by students, the data seem to outline a more complex and articulated picture. Beside the three groups of responses presented above, a fourth one emerges from the interviews, which accounts for those students who reported to use both TLN and FN in addressing lecturers $(39 \%)$.

This option, labelled TLN/FN in Table 1 below, does not indicate that students use TLN and FN alternately with the same addressee, nor that their usage is a matter of randomness. Indeed, according to these informants, the choice of the appropriate vocative follows a precise pattern. TLN represents the unmarked $^{7}$ form of address towards lecturers and is employed as first choice to express deference and respect. At the same time, the usage of the more informal FN is also reported by those students, but is considered a marked strategy, since it is the result of an explicit invitation on the part of lecturers (usually lecturers give permission or introduce themselves with FN encouraging the usage). It may also reflect an increase in familiarity due to frequent interactions and collaborations (e.g. a project or a dissertation):

(4) 'Q: How do you address a male lecturer in class?

A: Sir but if I know them better I call them by their first names or obviously if I or Doctor [plus surname] [...] there's my my dissertation supervisor I call him [shortened first name] cause I know him.'

(Male student, 21 years old).

The responses provided by students can be summarized in the following table ${ }^{8}$ :

7 The dichotomy marked/unmarked has been extensively employed in investigations on the usage of address terms to describe the contrast between usual, agreed-upon forms (unmarked) and peculiar, emphatic forms (marked) (cf. Dickey 1997; Jaworski and Galasinski 2000; Clyne et al. 2006).

${ }^{8}$ The sum of the percentages exceeds $100 \%$ since students were able to give multiple answers. More precisely, 5 informants (28\%) reported to use both HON and TLN as formal strategies to express a high degree of respect towards lecturers. HON and TLN have been considered as two distinct formal categories in the table, which makes the percentages add up to $128 \%$. 
Table 1 - Students' address strategies towards lecturers

\begin{tabular}{|l|l|l|l|}
\hline HON & TLN & TLN/FN & FN \\
\hline$(5$ informants $)$ & $(7$ informants $)$ & $(7$ informants $)$ & $(4$ informants $)$ \\
$28 \%$ & $39 \%$ & $39 \%$ & $22 \%$ \\
\hline
\end{tabular}

The last strategy which is broadly employed in the address practice among students and teaching staff is the avoidance of any kind of vocative. This is generally considered a neutral way of address, as the speaker employs the second person pronoun you or other summoning expressions and gestures (e.g. 'Excuse me', raising hands, etc.) without conveying any explicit interpersonal meaning. All informants report to adopt the strategy of avoidance as a solution whenever they are not sure of the appropriate form to use or, more commonly, when they do not know the name of the addressee. A student commented on this point:

(5) 'I try to tend not to use [names] 'coz I'm so bad about with remembering names I try not to use names you can get a name wrong and you'll feel like an idiot I just try to use polite sort of phrases like Excuse me.'

(Male student, 21 years old).

The figures summarized in table 1 are consistent with the responses provided by lecturers, who acknowledge a great occurrence of formal vocatives on the part of students in interactions in the classroom, even though not all categories of forms are reported. In particular, the use of FN reaches $25 \%$ ( 2 informants) and is comparable to the one in Table 1, while the option TLN/FN increases up to $75 \%$ (6 informants) indicating the blurred boundaries in the use of formal and informal forms of address. The following comments exemplify it effectively:

(6) 'Well I think very few students call me by my first name I don't particularly mind if they do [...] very few call me by my first name [...] yeah [they call me] professor.'

(Male professor, 62 years old).

(7) 'I ask them [i.e. students] to address me as [first name] but they tend to start by calling me Doctor or Ms or often Professor.'

(Female lecturer, 49 years old).

To sum up, the data from the interviews reveal a preference for formal vocatives on the part of students in addressing lecturers. TLN and HON are considered to be the unmarked appropriate forms to express deference and respect. Conversely, the use of $\mathrm{FN}$ is less frequent and is perceived as marked by the majority of informants, since it is the result of an explicit invitation from lecturers or it signals an increase in familiarity. 


\subsection{Addressing instructors}

Other teaching figures whom students frequently have contact with are instructors, who are responsible of practical sessions and tutorials in laboratories. The group of instructors mainly comprises technicians, language assistants and $\mathrm{PhD}$ students who are usually involved in informal and personal relations with single students or with a small number of them. The rather informal nature of practical sessions is reflected in the strategies of address exploited by the majority of students (61\%), who indicate FN (and even diminutives in one informant's report) as the unmarked vocative form used towards male and female instructors.

On the other hand, formal vocatives (i.e. HON and TLN) are adopted as unique address strategies only by a small amount of students ( $6 \%$ for each category), while TLN (usually Mr, Mrs, Ms or Miss, only rarely Dr.) is more likely to coexist with the frequent FN in the students' repertoire (28\%).

The results are summarized in Table 2:

Table 2 - Students' address strategies towards instructors

\begin{tabular}{|l|l|l|l|}
\hline HON & TLN & TLN/FN & FN \\
\hline$(1$ informant $)$ & $(1$ informant $)$ & $(5$ informants $)$ & $(11$ informants $)$ \\
$6 \%$ & $6 \%$ & $28 \%$ & $61 \%$ \\
\hline
\end{tabular}

A certain parallelism may be found between the strategies employed in addressing lecturers and instructors. In both cases two opposite forms of address coexist (TLN and $\mathrm{FN}$ ), although in the case of instructors the unmarked strategy is clearly FN, which is preferred by the majority of students, whereas the use of TLN is less common and varies in terms of formality expressed (few professional titles and frequent personal titles). The two categories of vocative alternate according to the frequency of contacts both for lecturers and for instructors, moving from the more distancing TLN to the more intimate and personal FN. Moreover, as we have seen in the case of lecturers, the choice of vocatives for instructors is not always a matter of deliberate decisions on the part of students, but it is determined by the way the addressees introduce themselves or by an explicit permission. Some students in fact comment that they 'are allowed to call them [i.e. instructors] by their first name' (Female student, 19 years old), others simply adopt the terms used in introduction:

(8) 'It depends how they've [i.e. instructors] been introduced usually if they've been introduced themselves by their first name I'll call them by their first name otherwise it'd be doctor or mister if that's how they've been introduced.'

(Male student, 23 years old).

Thus, it is necessary to specify that students have access to informal modes of address in interactions with instructors, but this opportunity is still regulated by the more powerful party of the dyad, namely the person who occupies a higher position in the academic hierarchy. 


\subsection{Addressing students}

Let's now turn to the strategies employed by members of the teaching staff in addressing students. All students report of being addressed by their FN, both inside the classroom and generally in interactions on campus. The results are fully confirmed by lecturers themselves, who acknowledge the use of FN towards students not only in face to face conversations, but also in email correspondence.

On the other hand, some of the answers record the employment of the avoidance strategy on the part of teachers, who might not know the name of every single students, especially in lectures with a large audience. This is however considered a temporary matter, as the natural development of teaching and learning activities during the terms creates opportunities for more personal interactions among students and lecturers, in which students' names are found out and used.

Although not very common, another pattern of address emerged from the interviews is the use of expressions of familiarity, which increases the general informality typical of many interactions among students and members of the teaching staff. Three male students report of being occasionally addressed with the camaraderie form mate and other informal expressions like young man and young chap by male lecturers, while two female students comment of having received the epithet young lady in teaching situations. Such expressions of familiarity are rarely used in interactions in the classroom and are more likely to be considered exceptional by students.

(9) 'Some people go young lady though no one will turn around.'

(Female student, 20 years old).

(10) 'I know someone [i.e. male lecturer] who would say young man or young chap.' (Male student, 28 years old).

(11) 'There was one guy in chemistry who did [i.e. used the vocative mate] but he was the only one it's not common.'

(Male student, 20 years old).

and even inappropriate in some situations:

(12) 'He's [i.e. male lecturer] called me mate once actually one of my tutors [...] he called me mate just I don't remember thinking of it seems to be weird [...] a little bit overfamiliar yeah.'

(Male student, 31 years old).

The use of these terms is possibly influenced by the personal relations existing between interactants or they may be employed in utterances to achieve particular expressive effects. At any rate, the occurrence of these expressions of familiarity is a signal of the growing informality in the academic setting and, as for vocatives like mate, it can be interpreted as a gradual fading out of the class connotation associated with camaraderie forms (cf. Formentelli 2007 on the spreading of mate in interactions).

The data collected through interviews with members of the teaching staff seems to confirm the usage of familiarizers and other vocatives of affection in addressing students, but only occasionally and with ironical or jocular tones 
(13) 'I wouldn't call a student mate except maybe occasionally as a joke.'

(Male professor, 62 years old).

or when participants know each other well:

(14) 'It's interesting I do with female students whom I know reasonably well I use my dear yes male students who I know reasonably well very rarely no not yeah no not that rarely I would use chum C-H-U-M yeah [...] a chum is someone who you have a slightly more really is more of a relationship.'

(Male lecturer, 63 years old).

Finally, the informal expressions guys and you guys seem to be commonly used by both male and female lecturers, who employ them as collective vocatives to address a mixed group of students in class.

\subsection{Data from video-recordings}

Further comments on the address strategies employed in classroom interactions need to be made on the basis of data provided through video-recordings of real teaching activities, which have been included in the corpus to cross-check the responses of informants.

As far as the strategies employed by lecturers are concerned, the occurrence of forms in the transcriptions confirms an extensive use of informal vocatives towards students, who are mainly addressed by their FN and only occasionally by means of familiarizers and jocular expressions:

(15) 'you finished correcting [shortened first name ${ }_{1}$ ? [First name 2 ] are you alright? is it all in? [...] how about you [first name $\left.e_{3}\right]$ ? [...] okay so the backline the back row is all there is it that's great.'

(Lecturer to students).

(16) 'Why do you think that sorry I was picking on you sorry mate why do you think that figure exists?.'

(Lecturer to student).

(17) 'Yeah going along the table to your oh you've already had a go mate.'

(Lecturer to student).

(18) 'Well thanks very much guys that was an excellent presentation well done.' (Lecturer to students).

Avoidance strategies are also frequent, especially in lectures taking place in theatres and big rooms with a large audience, which generally limit the access to people's identities and the possibility to use the addresses' personal names. Spatial deixis and ad hoc expressions are also exploited in some cases to identify the addressees according to their position in the class and their physical appearance:

(19) 'there reading the Daily Telegraph or something sixty seventy what do you think the most important part of the cardiac cycle for these patients is?' 
(Lecturer to student).

(20) 'What are you going to do about the airway? Let's let's have some offers where did we get to we got to you're looking particularly bored young lady with a hand on her chin punching herself to keep awake.'

(Lecturer to student).

Students' address practice, on the other hand, does not exhibit the variety of forms expected from the information reported in the interviews. In the video-recordings in fact, nominal forms of address are rare and limited to interactions among students. No TLN, HON or FN are employed as vocatives towards lecturers and instructors, who are usually addressed by means of the pronominal form you and other summoning strategies (e.g. the expression 'Excuse me', raising a hand, seeking eye-contact).

Only few instances of TLN appear, but they serve the function of terms of reference (i.e. they refer to a lecturer external to the interaction) and, although they would probably signal an equivalent level of formality also in the use of vocatives, they cannot be considered proper examples of address:

(21) 'Good afternoon while Doug [i.e. a student] is setting up I'm just going to introduce our topic as Doctor [surname] said we're going to talk about preoperative assessment.'

(Student to students).

Given that students reasonably know the names of their lecturers, for example through the university website or directly from the secretaries of the departments, two opposite hypotheses can be proposed to explain students' extensive use of avoidance strategies at the expense of nominal forms.

The first one refers to contextual constraints such as the structure of the teaching encounters and the roles of speaker and addressee in the exchange. In particular in lectures and tutorials, where students are involved in one-to-one interactions mainly with the tutor and not with other students, the receiver of the message is clearly identified. Thus nominal vocatives used to select the interlocutor are perceived as superfluous and left out. In seminars instead, which entail debates where students and lecturer discuss their opinions with everybody, the usage of personal names would be expected to avoid confusion in defining the intended addressee. However, vocatives are dispreferred by students, seemingly because they impede the fluent flowing of discussion. Non-verbal strategies, such as gestures, eye-contact and position of the body are exploited along with pronouns to guarantee the successful management of the interaction.

The second hypothesis, on the other hand, has to do with the interpersonal meaning expressed by personal names, whose usage obliges speakers to express social deixis explicitly. Students seem to prefer the use of the second-person pronoun, which is more neutral and allows them to avoid the problem of choosing the appropriate level of formality embodied in FN, TLN and HON. Hence, the use of pronominal address is a matter of deliberate choice on the part of students and is not due to contextual constraints.

The two hypotheses are not mutually exclusive and both participate to different extents in determining the choice of the address strategy in interactions with lecturers. The second hypothesis, however, which puts forward the influence of the interpersonal 
meaning and the deliberate choice of students, appears to outweigh the first one of structural and contextual constraints. I will return to this point in the following sections, in which the distribution of address strategies in the classroom is discussed.

\subsection{Asymmetry in interactions in the classroom}

One important result which emerges from the corpus of data concerns the distribution of address strategies in interactions among students and members of the teaching staff. A clear asymmetry in the choice of address forms, i.e. the non-reciprocal use of forms or the recourse to strategies expressing unequal levels of formality/informality, is reported in interviews as the common, unmarked practice in the classroom. Students, in fact, address lecturers mainly with formal vocatives (TLN and HON) and receive informal expressions in return (FN and familiarizers). The use of FN towards members of the teaching staff is perceived as marked, especially on the part of students, which consider it a practice to be achieved over time, as the relationship develops, and normally initiated by the person with higher status. For this reason, also the reciprocal usage of FN in students/instructors interactions is only apparently a matter of symmetry, since in most of cases it is the result of explicit invitations and follows permissions given from the more powerful party in the dyad. Moreover, camaraderie forms and endearments are occasionally employed in address by the teaching staff but never by students, thus establishing a certain imbalance also in informality.

This trend of asymmetry is confirmed by evidence from the video-recordings included in the corpus, although the address strategies employed in real teaching activities do not perfectly overlap with the ones reported by informants. Lecturers make an extensive use of FN and other informal expressions in class (familiarizers, but also spatial deixis), along with pronominal forms (you, you all, some of you, all of you, etc.) and non-verbal strategies (gestures, eye-contact, position of the body, etc.). Students, on their part, limit their address practice to lecturers to strategies of avoidance, in particular the second-person pronoun and non-verbal actions, and do not express any stance of formality or informality explicitly. This lack of vocatives in students' address, however, does not prevent the classification of the distribution of address strategies in the classroom as asymmetrical.

As was anticipated in the previous section, students' exploitation of avoidance strategies is only in minimal part due to contextual constraints, since students are supposed to know their teachers' identities. Further evidence of the limited influence of the context on the occurrence of avoidance strategies can be found in the linguistic behaviour of lecturers, who seem to switch from pronominal forms to $\mathrm{FN}$ as soon as they get to know students' identities. A more plausible explanation underlying students' preference for avoidance strategies in addressing lecturers seems to be the deliberate choice not to commit to the expression of any interpersonal stance. In fact, students do employ FN as address strategy to address other students in class, but avoid nominal vocatives when lecturers are concerned.

Given the lack of explicit morphemes indexing politeness in the English pronominal paradigm, the second-person pronoun you represents an effective compromise between formal and informal address (cf. also Wierzbicka 1991: 47-48), of which students take full advantage in addressing lecturers. Yet the 'neutrality' of you is restricted to the semantic and structural levels of the language, as the deliberate choice of such strategy 
within a wider repertoire of vocatives at their disposal (namely TLN, HON, FN) inevitably produces non-neutral inferences in interpersonal communication. The continuous exploitation of avoidance strategies when personal names are known is all but a neutral practice, since the use of personal names is expected and almost obligatory among people who know each other (Ervin-Tripp 1972) ${ }^{9}$. Therefore, students' preference for avoidance strategies can be interpreted as an attempt to find a neutral compromise between formality (indexed by the use of HON and TLN) and informality (expressed by the use of FN). At the same time however, this behaviour indirectly contributes to establish and maintain asymmetry in interactions, since students, who are often addressed by their FN in the classroom, prefer not to employ reciprocal FN in addressing lecturers, although the use of informal vocatives is encouraged in many occasions.

Other findings that hint at an asymmetrical organization of the address practice in interactions in the classroom concern the distribution of non-verbal strategies, which are employed in different ways by participants. For instance, raising hands is frequent on the part of students when they want to get lecturers' attention and ask for permission to intervene, whereas pointing with the finger to identify the addressee has been noticed in lecturers but never in students. This difference in the employment of addressing gestures is again a signal of the uneven distribution of power in the dyad and of the hierarchical structure of academic interactions.

\section{Discussion and conclusion}

Comparing the distribution of strategies emerging from this brief account to the models put forward by previous studies on the phenomenon of address, some comments can be made. As for the model of power and solidarity semantics proposed by Brown and Gilman (1972 [1960]) in the 1960s for German, French and Italian, and adapted to American English by Brown and Ford (1964 [1961]) in the same years, it does not seem to apply fully satisfactory to the address practice in the students/lecturers interactions examined above. Contrary to what the authors claim in their work, the vertical dimension of non-reciprocal address exemplified in the asymmetrical distribution of formal and informal strategies does not appear to recede in academic interactions at the University of Reading, but rather emerges as the frequent, unmarked practice in the classroom.

Moreover, the horizontal dimension of reciprocity of address described in the models is clearly not valid for what has been recorded in the British academic setting examined. Firstly, a reciprocal usage of formal vocatives indicating distance has not been reported by informants, nor has been found in video-recordings. Secondly, the mutual use of informal strategies indexing familiarity is not as frequent as one may expect from the previous models and is described as marked by respondents.

Although some students evaluate reciprocal informal address as a stimulating and privileged condition for studying and collaborating with their lecturers in a relaxed atmosphere, the majority of them sticks to formal strategies as a way to convey respect and deference. This appears to be particularly true for younger students of the first year,

${ }^{9}$ In Ervin-Tripp's model the avoidance of vocative is expected only when the identity of the addressee is unknown. Her study, however, refers to American English and needs to be employed with care in discussions involving British linguistic norms and culture. 
who feel more at ease in maintaining the non-reciprocal use of address forms typical of secondary schools (cf. Bargiela et al. 2002: 14n). Also lecturers show opposing opinions about reciprocal informal address, as some encourage the use of FN from students, while others are more careful and underline the necessity of boundaries that signal the different roles in the classroom. These results are even more in contrast with a recent survey carried out by Murray (2002: 48) on address in American English, who maintains that mutual FN is the most frequent address strategy in American English among people of different age and occupational status.

This point establishes a link with a claim made by Bargiela et al. (2002: 4) about the spreading of reciprocal FN in British culture under the influence of American norms. The authors acknowledge the increasing familiarity in addressing "relative strangers" in certain contexts of interaction such as business encounters, but also underline that British people often find it uncomfortable and even inappropriate to address nonacquainted people by their first name. The results of this survey seem to confirm this trend in the domain of academic interactions, where the reciprocal use of familiar address strategies is dispreferred.

Another observation concerns the influence of the power dimension in address practice. Consistently with Brown and Gilman's model, the difference of power regulates the choice and distribution of address terms at the University of Reading. In particular, formal strategies are employed in addressing the more powerful party, while informal strategies are used downwards to less powerful addressees. Moreover, the switch to reciprocal informal vocatives is initiated by the superior and never by the inferior.

However, a new component emerges in the academic interactions analyzed in this survey, which was not accounted for in the previous model and which brings into question the balance of power within the dyad. I refer to the unwillingness of students to use familiar forms towards lecturers, which has been outlined in the analysis of video-recordings. The wide-spread employment of avoidance strategies towards lecturers, who most probably encourage the use of FN (at least according to their responses in the interviews), results in the maintenance of asymmetry in address practice. This pattern diverges from the 'traditional' non-reciprocal distribution of forms, since it is not established from above by superiors (i.e. the teaching staff) but is the consequence of the deliberate resistance from the less powerful party in the interaction (i.e. students). Finally, it calls into question one of the strongest claims put forward by Brown and Gilman's model and by most of the previous studies: The rapid evolution from a distancing address practice to an intimate and familiar one. In the case of academic interactions at the University of Reading, the quick movement to reciprocal informal address is not necessarily the expected solution nor the ideal achievements for speakers, but it is somehow resisted or delayed in time.

To sum up, the findings about the address strategies employed in classroom interactions at the University of Reading show linguistic patterns which are different from the ones described over the decades for American English. In particular, British speakers of this university appear to be more keen on maintaining the asymmetrical distribution of forms and perceive reciprocal informal address as a marked choice. Moreover, data call into question the efficacy of previous models in the description of the phenomenon, which only partially fit the distribution of address terms in the British academic setting and need to be modified in order to account for other important components, such as the role of the less powerful party in the interaction. On the light 
of the new insights presented above, further research based on a larger corpus of data from other universities in Britain would be fully justified, in order to provide further evidence which would validate this description of address practice and extend it to British academic interactions in general.

\section{References}

Axelson, Elizabeth (2007) Vocatives: A double-edged strategy in intercultural discourse among graduate students. Pragmatics 17.1: 95-122.

Bargiela, Francesca, Corinne Boz, Lily Gokzadze, Abdurrahman Hamza, Sara Mills, and Nino Rukhadze (2002) Ethnocentrism, politeness and naming strategies. Working papers on the web 3. http://extra.shu.ac.uk/wpw/politeness/bargiela.htm. (Accessed $16^{\text {th }}$ February 2008).

Biber, Douglas, Stig Johansson, Geoffrey Leech, Susan Conrad, and Edward Finegan (1999) The Longman grammar of spoken and written English. London: Longman.

Braun, Friederike (1988) Terms of address: Problems of patterns and usage in various languages and cultures. Berlin: Mouton de Gruyter.

Brown, Roger, and Albert Gilman (1960) The pronoun of power and solidarity. In Thomas A. Sebeok (ed.), Style in language. Cambridge, Massachusetts: Technology Press of Massachusetts Institute of Technology, pp. 253-276. Reprinted in Pier Paolo Giglioli (ed.) (1972) Language and social context. Harmondsworth, U.K.: Penguin, pp. 252-82.

Brown, Roger, and Marguerite Ford (1961) Address in American English. Journal of abnormal and social psychology 62: 375-385. Reprinted in Dell Hymes (ed.) (1964) Language in culture and society. New York: Harper and Row, pp. 234-244.

Clyne, Michael, Catrin Norrby, and Jane Warren (2009) Language and human relations. Styles of address in contemporary language. Cambridge: Cambridge University Press.

Clyne, Michael, Heinz L. Kretzenbacher, Catrin Norrby, and Jane Warren (2004) Address in some western European languages. In Christo Moskovsky (ed.), Proceedings of the 2003 conference of the Australian Linguistic Society. http://au.geocities.com/austlingsoc/proceedings/als2003/clyne.pdf (Accessed on $16^{\text {th }}$ February 2008).

Clyne, Michael, Heinz-Leo Kretzenbacher, Catrin Norrby, and Doris Schüpbach (2006) Perceptions of variation and change in German and Swedish address. Journal of sociolinguistics 10.3: 287-319.

Dickey, Eleanor (1997) Forms of address and terms of reference. Journal of linguistics 33.2: 255-274.

Dunkling, Leslie (1990) A dictionary of epithets and terms of address. London: Routledge.

Duranti, Alessandro (1997) Linguistic anthropology. Cambridge: Cambridge University Press.

Ervin-Tripp, Susan (1986) On sociolinguistic rules: Alternation and co-occurrences. In John J. Gumperz and Dell Hymes (eds.), Directions in sociolinguistics: The ethnography of communication. (Reissued with corrections and additions). Oxford, U.K.: Blackwell, pp. 213-250.

Formentelli, Maicol (2007) The vocative mate in contemporary English: A corpus based study. In Andrea Sansò (ed.), Language resources and linguistic theory. Milano: Franco Angeli, pp. 180-199.

Gilman, Albert, and Roger Brown (1958) Who says 'Tu' to whom? ETC: A review of general semantics 15.3: 169-174. 
Goldthorpe, John Harry (2000) Social class and the differentiation of employment contracts. In John Harry Goldthorpe (ed.), On sociology: Numbers, narratives, and the integration of research and theory. Oxford: Oxford University Press, pp. 206-229.

Gumperz, John J., and Dell Hymes (eds.) (1972) Directions in sociolinguistics: The ethnography of communication. New York: Holt, Rinehart and Winston.

Helmbrecht, Johannes (2003) Politeness distinctions in second person pronouns. In Friedrich Lenz (ed.), Deictic conceptualization of space, time and person. (Pragmatics and beyond). Amsterdam: Benjamins Publishing Company, pp. 185-203.

Helmbrecht, Johannes (2005) Politeness distinctions in personal pronouns. In Martin Haspelmath, Bernard Comrie, Matthew S. Dryer and David Gil (eds.), The World Atlas of Language Structures. Oxford: Oxford University Press, pp. 186-190.

Helmbrecht, Johannes (2006) On the development of Standard Average European (SAE) - The case of polite pronouns. Paper presented at the $28^{\text {th }}$ annual meeting of the DGfS, University of Bielefeld, Germany. 22-24 February 2006.

Hickey, Leo, and Miranda Stewart (eds.) (2004) Politeness in Europe. Clevedon, U.K.: Multilingual Matters.

Hickey, Raymond (2002) Rectifying a standard deficiency. Second-person pronominal distinctions in varieties of English. In Irma Taavitsainen and Andreas H. Jucker (eds.), Diachronic perspectives on address term systems. Amsterdam: John Benjamins Publishing Company, pp. 343-374.

Jaworski, Adam, and Dariusz Galasiński (2000) Vocative address forms and ideological legitimization in political debates. Discourse studies 2.1: 35-53.

Leech, Geoffrey (1999) The distribution and function of vocatives in American and British English conversation. In Hilde Hasselgård and Signe Oksefjell (eds.), Out of Corpora. Studies in Honour of Stig Johansson. Amsterdam: Rodopi, pp. 107-118.

McConnell-Ginet, Sally (2003) "What's in a Name?" Social labelling and gender practices". In Janet Holmes and Miriam Meyerhoff (eds.), The handbook of language and gender. Oxford: Blackwell, pp. 69-97.

Mühlhäusler, Peter, and Rom Harré (1990) Pronouns and people: The linguistic construction of social and personal identity. Oxford: Basil Blackwell.

Murray, Thomas E. (2002) A new look at address in American English: The rules have changed. Names 50.1: 43-61.

Philipsen, Gerry, and Michael Huspek (1985) A bibliography of sociolinguistic studies of personal address. Anthropological linguistics 27: 94-101.

Pieper, Ursula (1990) Homologie, Homöologie und Heterologie im Anredeverhalten: Anrede im Deutschen, Dänischen und Polnischen. Zeitschrift für germanistische Linguistik 18.1: 1-12.

Saville-Troike, Muriel (2003) The ethnography of communication: An introduction. 3ed. Oxford: Blackwell.

Sutton, Laurel A. (1995) Bitches and skankly hobags: The place of women in contemporary slang. In Kira Hall and Mary Bucholtz (eds.), Gender articulated. Language and the socially constructed self. London: Routledge, pp. 279-96.

Wales, Katie (1996) Personal pronouns in present-day English. Cambridge: Cambridge University Press. 
Warren, Jane, Michael Clyne, Heinz L. Kretzenbacher, and Catrin Norrby (2007) The underlying pragmatics of address usage: Comparing and contrasting English with French, German and Swedish. Paper presented at the $10^{\text {th }}$ International Pragmatics Conference, Göteborg, Sweden. 8-13 July 2007.

Wierzbicka, Anna (1991) Cross-cultural pragmatics. The semantics of human interaction. Berlin: Mouton de Gruyter.

Zwicky, Arnold M. (1974) Hey, Whatsyourname!. In Michael W. La Galy, Robert A. Fox, Anthony Bruck (eds.), Papers from the tenth regional meeting of the Chicago Linguistic Society, pp. 787-801. 